\title{
Osteointegração da hidroxiapatita sintética no processo alveolar da mandíbula de cães: aspectos clínicos e radiográficos
}

\author{
[Osteointegration of synthetic hydroxyapatite in alveolar process of the jaw of dogs: \\ clinical and radiographic aspects] \\ T.S. Duarte ${ }^{1}$, A.P.B. Borges ${ }^{2 *}$, M.S.L. Lavor $^{1}$, R. Filgueiras ${ }^{1}$, A.C. Tsiomis ${ }^{1}$ \\ G. Fófano ${ }^{1}$, M.E. Odenthal ${ }^{1}$, K.C.S. Pontesl ${ }^{1}$ \\ ${ }^{1}$ Aluno de pós-graduação - UFV - Viçosa, MG \\ ${ }^{2}$ Departamento de Veterinária - UFV \\ Av. P.H. Rolfs, $\mathrm{s} / \mathrm{n}$ \\ 36570-000 - Viçosa, MG
}

\begin{abstract}
RESUMO
Avaliou-se o efeito da hidroxiapatita sintética na regeneração do osso alveolar e o efeito no tecido vivo de cães. Em dois grupos de 14 cães adultos hígidos, pesando entre 10 e $15 \mathrm{~kg}$, foram criados defeitos de $6 \times 5 \mathrm{~mm}$ na superfície vestibular do processo alveolar mandibular direito até atingir a raiz do quarto pré-molar. Em um grupo (tratado), o defeito foi preenchido com hidroxiapatita sintética; o grupo sem tratamento foi usado como controle. Efetuaram-se avaliações clínicas diárias durante uma semana, avaliações radiográficas após a cirurgia e aos oito, 21, 42, 60, 90 e 120 dias do pós-operatório. Vinte e quatro cães apresentaram inflamação, sendo a recuperação no grupo tratado mais lenta. Todos os animais tiveram sangramento com a hidroxiapatita. No grupo-controle houve aumento crescente da radiopacidade dos defeitos, no entanto, aos 120 dias do pósoperatório, os defeitos ainda eram visíveis. No grupo tratado, inicialmente a radiopacidade foi maior que a do osso normal, com diminuição gradual até se tornar semelhante à do osso vizinho, 60 dias após a cirurgia. A hidroxiapatita T290800-1 acelerou o preenchimento do defeito provocado no processo alveolar e acarretou inflamação e hemorragia gengival, o que, no entanto, não contra-indicou o seu uso.
\end{abstract}

Palavras-chave: cão, hidroxiapatita, processo alveolar, radiopacidade

\begin{abstract}
The effect of the synthetic hydroxyapatite on the regeneration of the alveolar bone of dogs and on the alive tissue were evaluated. In two groups of 14 adult healthy dogs, weighing from 10 to $15 \mathrm{~kg}$, some defects around $6 \times 5 \mathrm{~mm}$ were provoked on the vestibular surface of the right jaw alveolar process until reaching the root of the forth premolar. In one group, the defect was infilled with synthetic hydroxyapatite. The no treated group dogs were used as control. Clinical evaluations were daily performed over one week, as well as radiographic evaluations after surgery, and on 8,21, 42, 60, 90 and 120 days after surgery. Twenty-four dogs showed inflammation and the recovery in the treated group was slower than in the control group. Bleeding at the presence of hydroxyapatite was observed in all the animals. The radiographic examination presented an increasing radiopacity in the control group; however, this defect was still visible on day 120 after operation. Initially, in the treated group, radiopacity was higher than that of the normal bone and a gradual decrease occurred until becoming similar to the adjacent bone on day 60 days after surgery. The hydroxyapatite T290800-1 accelerated the infilling of the defect provoked in the alveolar process and caused gingival inflammation and hemorrhage; however, this does not contraindicate its use.
\end{abstract}

Keywords: dog, hydroxyapatite, alveolar process, radiopacity

Recebido em 17 de novembro de 2004

Aceito 20 de setembro de 2006

*Autor para correspondência (corresponding author)

E-mail: andrea@ufv.br 


\section{INTRODUÇÃO}

A doença periodontal, os traumas acidentais e os traumas cirúrgicos provocados pela extração de dentes são algumas das causas da perda do osso alveolar. Cerca de $85 \%$ dos cães e gatos com mais de três anos de idade apresentam algum grau de enfermidade periodontal, e essa é, sem dúvida, a principal causa da perda do osso alveolar e das perdas dentais (Emily et al., 1999).

O processo alveolar é um dos componentes do periodonto e, portanto, contribui para a inserção dos dentes na maxila e na mandíbula (Terranova et al., 1997). O processo é formado pela junção do osso alveolar, que consiste em uma fina faixa de osso cortical, com o alvéolo (Emily et al., 1999). O osso alveolar funde-se com as placas corticais nas faces vestibular e lingual, através de trabéculas de osso esponjoso. A porção esponjosa do processo alveolar é contínua com a porção esponjosa da maxila e da mandíbula (Terranova et al., 1997).

Os auto-enxertos ósseos são bastante requeridos em cirurgias maxilofaciais, craniofaciais, orais e em cirurgias plásticas. No entanto, o principal problema relacionado a esse procedimento é a morbidade que acomete o local doador (Orr et al., 2001). Os aloenxertos possuem como desvantagem o risco de transmissão de doenças e rejeição (Jensen et al., 1996).

Com isto, a necessidade de utilizar implantes como forma de tratamento para várias doenças ósseas torna fundamental o entendimento da interação do biomaterial com o ambiente vivo. A partir desse conhecimento, é possível a produção de implantes compatíveis com a saúde. Cerâmicas como a hidroxiapatita sintética têm sido avaliadas em defeitos intra-ósseos humanos com resultados clínicos positivos (Yukna et al., 2000) e com o intuito de substituir os autoenxertos ósseos em cirurgias ortopédicas (Oonishi et al., 1997).

O objetivo deste trabalho foi estudar o efeito da hidroxiapatita sintética na regeneração do osso alveolar e na resposta do tecido vivo ao implante por meio de análises clínico-cirúrgicas e radiológicas.

\section{MATERIAL E MÉTODOS}

Em dois grupos de 14 cães adultos hígidos, pesando entre 10 a $14 \mathrm{~kg}$, foram criados defeitos de aproximadamente $6 \times 5 \mathrm{~mm}$ na superfície vestibular do processo alveolar. Os cuidados no momento do pré e pós-operatório, o protocolo anestésico e os procedimentos cirúrgicos para a criação do defeito e implantação da hidroxiapatita foram descritos por Duarte et al. (2006).

$\mathrm{Na}$ avaliação diária da ferida cirúrgica, nos primeiros sete dias do pós-operatório, foram aferidos o grau de reação inflamatória, baseado na presença de edema e dor, e o grau de hemorragia. Todas as variáveis foram classificadas em intensa, moderada, leve e ausente.

Foram realizadas radiografias da região operada com filme intra-oral, utilizando a técnica do paralelismo, com posicionamento oblíquo ventrolateral-dorsomedial direito após a cirurgia e aos 8, 21, 42, 60, 90 e 120 dias de pósoperatório, visando avaliar o processo de reparação óssea. Os animais foram sedados com acepromazina $1 \%{ }^{1}$ na dose de $0,1 \mathrm{mg} / \mathrm{kg}$, por via intravenosa, e anestesiados com pentobarbital $3 \%{ }^{2}$ em dose suficiente para permitir o procedimento. Os filmes dentais utilizados foram fixados em um suporte e posicionados na região lingual do quarto pré-molar direito.

As radiografias foram analisadas quanto à radiopacidade em diferentes graus, comparandose o defeito provocado com o osso vizinho, considerado normal. O grau de radiopacidade foi quantificado por meio de escores, variando de 0 a 4, em que: $0=$ ausente; $1=$ intensamente abaixo da radiopacidade do osso vizinho; $2=$ discretamente abaixo da radiopacidade do osso vizinho; $3=$ semelhanete à radiopacidade do osso vizinho; 4= acima da radiopacidade do osso vizinho.

Os resultados foram estudados por análise descritiva. Foram avaliados os graus de radiopacidade, nas diferentes datas, dos diferentes grupos. A análise dos resultados

\footnotetext{
${ }^{1}$ Acepran 0,1\% - Univet S.A. - Indústria Veterinária.

${ }^{2}$ Pentobabital sódico 3\% - Cristália Produtos Químicos e Farmacêuticos Ltda.
} 
clínico-cirúrgicos comparou, de maneira descritiva, a presença e a evolução da resposta inflamatória e da hemorragia.

\section{RESULTADOS E DISCUSSÃO}

Vinte e quatro animais apresentaram edema leve a moderado nos dois primeiros dias do póscirúrgico. Cinco do grupo tratado e um do grupocontrole continuaram apresentando edema leve até o último dia de avaliação. Os demais não apresentaram edema a partir do terceiro dia do pós-operatório.

As alterações associadas à dor foram de intensidade leve em oito cães do grupo tratado e em seis do grupo-controle nos primeiros dois dias. Apenas um cão do grupo tratado apresentou dor moderada no primeiro dia após a cirurgia. A partir do terceiro dia, nenhum animal, de ambos os grupos, manifestou dor. Embora, segundo Yamamoto et al. (2000), a hidroxiapatita possa provocar irritação mecânica, não houve diferença em relação à intensidade da dor nos dois grupos.

Apesar de Alliot et al. (1999) atribuírem a inflamação gengival no pós-operatório à ausência de higienização da cavidade oral em cães, a dor e o edema encontrados neste experimento pareceram ser decorrentes da manipulação dos tecidos moles, durante $\mathrm{o}$ procedimento cirúrgico, e da presença da hidroxiapatita, uma vez que todos receberam higienização diária.

Todos os animais tratados apresentaram sangramento intenso no momento em que o biomaterial entrou em contato com a gengiva e com as bordas do defeito periodontal. Seis cães tratados apresentaram hemorragia variando de leve a moderada imediatamente após o procedimento cirúrgico, perdurando até o sétimo dia de avaliação clínica. Quatro animais do grupo-controle tiveram hemorragia leve durante, no máximo, dois dias após a cirurgia.

Ao contrário do esperado, apenas em dois cães, um de cada grupo, contatou-se a presença de secreção purulenta na ferida cirúrgica a partir do quinto dia do pós-cirúrgico, perdurando até o sétimo dia de avaliação clínica. Segundo Brown et al. (1998), a contaminação bacteriana nos poros de hidroxiapatita pode impedir o crescimento ósseo no seu interior. No entanto, não foi observado qualquer atraso na regeneração óssea daqueles que apresentaram infecção. A deiscência de sutura encontrada em cinco animais do grupo tratado e em seis do grupocontrole foi atribuída à grande tensão no local associada à presença de edema e hemorragia gengival.

Após a cirurgia, o grau de radiopacidade do grupo-controle foi zero e o do grupo tratado foi quatro (Fig. 2A). Em conseqüência do elevado número atômico dos seus constituintes químicos, a hidroxiapatita apresenta radiopacidade maior que a do osso (Rawlings et al., 1998). No oitavo dia do pós-cirúrgico nos cães do grupo-controle, o grau de radiopacidade ainda era zero (Fig. 1A). $\mathrm{O}$ grupo tratado apresentou pontos de radiopacidade três ao centro e zero em toda a periferia do defeito periodontal (Fig. 2B).

Segundo Cullun et al. (1988) e Borges (1998), em todo processo de cicatrização óssea, inicialmente desenvolve-se tecido fibrovascular no foco da lesão, cuja radiopacidade é insuficiente para ser perceptível no exame radiográfico. Portanto, não se pode descartar a possibilidade de ocorrer regeneração óssea, nesse período no grupo-controle. No grupo tratado, houve, provavelmente, reabsorção da hidroxiapatita na periferia do defeito, com deposição de tecido fibrovascular precedendo a formação óssea. Um animal deste grupo teve radiopacidade zero em todo o defeito nesta data. Nele, houve hemorragia moderada até o último dia de avaliação, o que, possivelmente, resultou na perda da hidroxiapatita e na ausência de radiopacidade.

As radiografias subseqüentes do processo alveolar tratado revelaram diminuição da radiopacidade com o passar do tempo. Aos 21 dias, a radiopacidade atingiu grau dois no centro e grau zero na periferia do defeito. Com 42 dias, a radiopacidade voltou a aumentar, apresentando-se com grau dois até atingir grau três em todo o defeito, 60 dias após a cirurgia (Fig. 2C). Tal fato se repetiu aos 90 e 120 dias. Portanto, aos 60 dias, já se pôde observar, radiograficamente, a reparação óssea completa do processo alveolar de todos os cães tratados com a hidroxiapatita T290800-1. 
No grupo-controle, houve aumento gradativo da radiopacidade dos defeitos. Aos 21 dias do póscirúrgico, a radiopacidade foi de grau um (Fig. 1B). Com 42 dias, o defeito ainda era perceptível, no entanto observou-se arredondamento das bordas com radiopacidade dois na periferia e um no centro. Com 60, 90 e 120 dias, os defeitos ainda eram visíveis, apresentando radiopacidade dois (Fig. 1C).
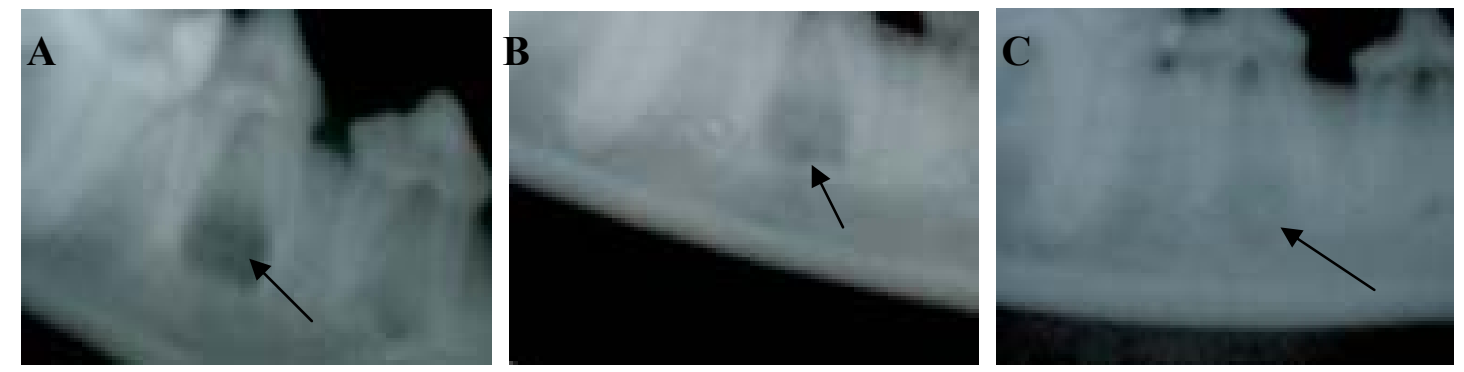

Figura 1. Radiografias obtidas da mandíbula de um cão do grupo-controle. (A) 8 dias, (B) 21 dias e (C) 120 dias após a confecção de um defeito no processo alveolar do quarto pré-molar direito (setas). Observa-se o arredondamento progressivo das bordas dos defeitos e o aumento da radiopacidade com o passar do tempo. Filme intra-oral utilizando a técnica do paralelismo.
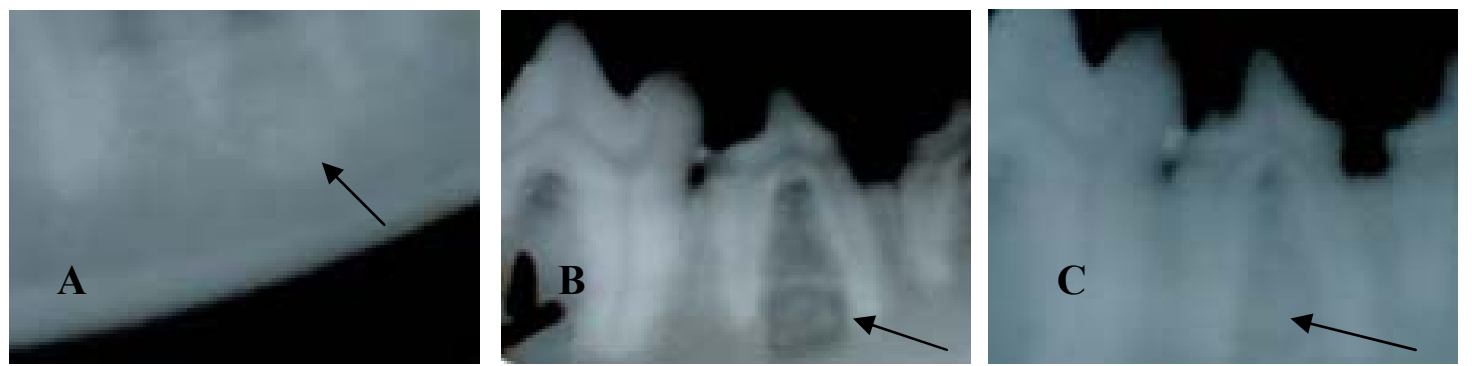

Figura 2. Radiografias obtidas da mandíbula de um cão do grupo tratado. (A) imediatamente após cirurgia, (B) 8 dias e (C) 60 dias após a confecção de um defeito no processo alveolar do quarto prémolar direito. Notar a evolução da radiopacidade do defeito ósseo (setas). Inicialmente ocorre uma diminuição da radiopacidade (com oito dias) e posteriormente um aumento gradual da densidade óssea (8 e 60 dias). Filme intra-oral utilizando a técnica do paralelismo.

\section{CONCLUSÕES}

Os resultados permitiram concluir que a hidroxiapatita T290800-1 acelera o preenchimento do defeito provocado no processo alveolar com um tecido de radiopacidade semelhante ao do osso e acarreta inflamação e hemorragia gengival, o que, no entanto, não contra-indica o seu uso.

\section{AGRADECIMENTOS}

Ao JHS Laboratório Químico, Belo Horizonte, MG.

\section{REFERÊNCIAS BIBLIOGRÁFICAS}

ALLIOT, B.; PIOTROWSKI, B.; MARIN, P. et al. Regeneration procedures in immediate transmucosal implants: an animal study. Int. J. Oral Maxillofac. Implants, v.14, p.841-848, 1999.

BORGES, A.P.B. O efeito da hidroxiapatita sintética na regeneração óssea de defeito provocado experimentalmente no terço proximal da tíbia de cães (Canis familiares): Estudo clínico-cirúrgico, radiológico e histológico por microscopia de luz e microscopia eletrônica de retrodispersão. 1998. 111f. Tese (Doutorado) Escola de Veterinária, Universidade Federal de Minas Gerais, Belo Horizonte. 
BROWN, G.D.; MEALEY, B.L.; NUMMIKOSKI, P.V. et al. Hydroxyapatite cement implant for regeneration of periodontal osseous defects in humans. J. Periodontol., v.69, p.146-157, 1998.

CULLUN, P.E.; FROST, D.E.; NEWLAND, T.B. et al. Evaluation of hydroxyapatite particles in repair of alveolar clefs in dogs. J. Oral Maxillofac. Surg., v.46, p.290-296, 1988.

DUARTE, T.S.; BORGES, A.P.B.; LAVOR, M.S.L. et al. Osteointegração da hidroxiapatita sintética no processo alveolar da mandíbula de cães. Aspectos histológicos. Arq. Bras. Med. Vet. Zootec., v.58, p.849-853, 2006.

EMILY, P.; SAN ROMÁN, F.; TROBO, J.I. et al. Periodontia. Enfermidade periodontal. In: ROMÁN, F. S. (Ed). Atlas de odontologia de pequenos animais. São Paulo: Manole, 1999. p.111-112.

JENSEN, S.S.; AABOE, M.; PINHOLT, E.M. et al. Tissue reaction and material characteristics of four bone substitutes. Int. J. Oral Maxillofac. Implants, v.11, p.55-66, 1996.

OONISHI, H.; KUSHITANI, S.; YASUKAWA, E. et al. Particulate bioglass compared with hydroxyapatite as a bone graft substitute. Clin. Orthop. Related Res., n.334, p.316-325, 1997.
ORR, T.E.; VILLARS, P.A.; MITCHELL, H.P. et al. Compressive properties of cancellous bone defects in rabbit model treated with particles of natural bone mineral and synthetic hydroxyapatite. Biomaterials, n.22, p.1953-1959, 2001.

RAWLINGS, C.E.; WILKINS, R.H.; HANKER, J.S. et al. Evaluation in cats of a new material for cranioplasty: a composite of plaster of paris and hydroxyapatite. J. Neurosurg., v.69, p.269-275, 1998.

TERRANOVA, V.P.; GOLDMAN, H.M.; LISTGARTEN, M.A. O aparelho de inserção periodontal. Estrutura, função e química. In: GENCO, R.J.; GOLDMAN, H.M.; COHEN, D.W. (Ed). Periodontia contemporânea. São Paulo: Santos Livraria, 1997. p.33-54.

YAMAMOTO, T.; ONGA, T.; MARUI, T. et al. Use of hydroxyapatite to fill cavities after excision of benign bone tumours. J. Bone Joint. Surg., v.8, p.1117-1120, 2000.

YUKNA, R.A.; KRAUSER, J.T.; CALLAN, D.P. et al. Multi-center clinical comparison of combination anorganic bovine-derived hydroxyapatite matriz (ABM)/ cell binding peptide (P-15) and $\mathrm{ABM}$ in human periodontal osseous defects. 6-month results. J. Periodontol., v.71, p.1671-1679, 2000. 